\title{
Comparative Studies of the Stabilities to Oxidation and Electrical Discharge between Ester Fluids and Transformer Oils
}

\author{
I. Fofana and J.S. N'cho \\ Canada Research Chair on Insulating Liquids and Mixed Dielectrics for Electrotechnology (ISOLIME), Université du Québec à \\ Chicoutimi, Québec, Canada. \\ J. C. Olivares-Galvan, R. Escarela-Perez \\ Depart. de Energia, Universidad Autonoma Metropolitana, Ciudad de Mexico, D.F., Mexico \\ jolivares@correo.azc.uam.mx \\ P. S. Georgilakis \\ School of Electrical and Computer Engineering, \\ National Technical University of Athens, \\ Athens, Greece.
}

\begin{abstract}
The growing demands for improved fire safety, source material sustainability, environment friendliness, and asset life extension have driven the research and development efforts of natural/synthetic esters, less-flammable fluids. This contribution reports some investigations on commercially available ester fluids. Many comparisons are made to the quality test results of mineral oil, as this is something we are all familiar with. The stability under electrical stress and the stability to aging of the insulating fluids were investigated. The gassing performance characteristics of natural ester fluids are far superior to those of conventional mineral oil. A significant reduction in insulation aging rate was observed with synthetic ester fluids.
\end{abstract}

\section{INTRODUCTION}

It is now an established fact that the service reliability of power transformers largely depends upon the condition of the oil-paper insulation.

While in service, both the liquid and solid insulation of windings undergo a slow but steady decay process under the impact of electrical, thermal, mechanical and chemical stresses. Recent studies have shown that the gassing of oil has an important side effect. The breakdown of hydrocarbon chains generates not only soluble gases, as it is currently believed, but also colloidal suspensions. The chemical aggressiveness of oxygen is responsible for the formation of soluble oxidation products as well as insoluble sludge which are detrimental to the solid insulation. Both types of unnoticed substances are irreversibly retained by cellulose insulation and generate hot spots.

In today's economic climate, it is important to know the condition, by means of suitable diagnostic tests, of the liquid impregnated paper usable as primary insulation in

The authors would like to thank MI Materials (United Kingdom) for their support in materials. transformers. The development of several new laboratory testing procedures for insulating liquids over the past years has been the rewarding result of a cooperative research project designed to extend the life expectancy of aging power transformers by eliminating the causes of premature deterioration. Assessing the outcome of oxidation reactions solely by measuring the organic acidity and interfacial tension of oil (both more than thirty years old), the foreseeable formation of the colloidal sludge and $\mathrm{x}$-waxes was ignored.

Knowledge of the resistance to gassing of insulating fluids under high electrical stress is of upmost important to both electrical-equipments designers and operating engineers.

\section{HISTORY OF TRANSFORMER FLUIDS}

The early transformers, produced in 1884 , were of dry type ones $[1,2]$. Petroleum oil was used on an experimental basis in the insulation of three-phase transformers early in 1891. However, at the end of the XIX ${ }^{\mathrm{e}}$ century, transformers were still isolated / ventilated with air. Due to the increasing demand of electric energy and the growing power transmission networks, air-insulated transformers became large. To size down their volume, petroleum oil application in power transformers was generalized from 1905 [1, 2]. Mineral oil, however, did not provide the necessary fire protection.

Between 1930 and the mid seventies, non-flammable liquids like PCB were used for insulation purposes. During the 1970s it was recognised that PCBs can be hazardous to people, animals and the environment. Even more frightening was the fact that, PCBs can form dioxins during an incomplete combustion. Since that time researchers in the 
transformer industry have tried countless combinations of chemicals to remove and replace the PCBs in the already built older transformers and to find new liquids for the filling of new transformers. High flash point (HFP) liquids also known as "less flammable" liquids (natural/synthetic ester and silicon fluids) were then introduced. Qualifying fluids must meet a minimum criterion of $300{ }^{\circ} \mathrm{C}$ open-cup fire point [3].

Esters are a broad class of organic compounds synthesized from organic acids and alcohols. The two main categories are synthetic and natural esters.

Synthetic esters, most commonly polyol (pentaerythritol) are generally limited to traction and mobile transformers and other special applications due to their high costs compared to other less-flammable fluids.

Attractive sources of natural esters are edible seed-based oils. Seed oils esters susceptibility to oxidation has been a primary obstacle to their utilization as dielectric fluid. However, suitable fluid additives and minor design modifications compensate for their characteristic. Many natural esters therefore contain additive packages consisting of chemicals to reduce the pour point and aid in oxygen stability, and, in some cases they have an antimicrobial agent or copper deactivators. This contrasts with mineral oil which has either no additives or merely oxidation inhibitors. It is not known if any adverse characteristics exist when natural esters are used in transformers over a long period.

\section{STABILITY UNDER ELECTRIC STRESS}

The amount of gases evolved under the impact of electrical stress by a sample of fluid was accurately measurable by using the ASTM Test Method D6180 [4], which simulate conditions close to real life conditions. The dynamics of gassing are visualized on the screen of a computer during the test. Various fluids properties such as the Dielectric Dissipation Factor (DDF) [5], at line frequency $(60 \mathrm{~Hz})$ and $100^{\circ} \mathrm{C}$, the Dissolved Decay Products (DDP) [6], Turbidity [7], Interfacial Tension (IFT) [8], and Water content [9] were measured before and after voltage application to assess the discharge deleterious impact. The Dielectric Dissipation Factor measurements were performed with the Insulation Diagnostic Analyzer IDA200 [10] using the liquid test cell type 2903 for liquid insulants manufactured by Tettex. This test cell, equipped with guard rings, were designed in accordance with the specifications of VDE (Verband Deutsh Elektrotechnik) 0303, 0370 and the recommendations of CIGRE, IEC and ISO, as well as with ASTM standards. A ratio turbidimetric optical system is used to measure the turbidity of insulating fluids relative to turbidity standards. The dissolved decay products are determined by a scanning spectrophotometer [7].

Fluids samples collected from various manufacturers were considered for these investigations. A naphtenic-based mineral based oil, natural and synthetic ester fluids were considered in these investigations (Table 1). It should be noticed that MO always represents Mineral Oil, NE for Natural Ester, while SE stands for Synthetic Ester.
The properties of esters or silicones fluids cannot be correlated directly to that of a mineral oil as their chemistries are very different. However, some tests used to evaluate mineral oil are generally used to evaluate ester fluids [11].

Basically, the gassing of an insulating fluid under electrical discharge depends on the chemical composition of the fluid, electric field stress, temperature and time. The dynamics of the fluids gassing was visualized on the screen of a computer during the test and summarized in Figure 1. The pressure increases inside the discharge cell indicates the amount of gases evolved due to the primary decomposition of un-stable molecules. \begin{tabular}{llllrl} 
TABLE I. SELECTED & \multicolumn{2}{c}{ PHYSICOCHEMICAL } & AND & ELECTRICAL \\
CHARACTERISTICS OF & THE INVESTIGATED & FLUIDS, & PROVIDED & BY
\end{tabular} MANUFACTURERS.

\begin{tabular}{|c|c|c|c|}
\hline & Oil & $\mathrm{NE}$ & $\mathrm{SE}$ \\
\hline Dissipation factor & & - & - \\
\hline @ $60 \mathrm{~Hz}, 100^{\circ} \mathrm{C}, \mathrm{D} 924$ & 0.07 & & \\
\hline (a) $50 \mathrm{~Hz}, 90^{\circ} \mathrm{C}, \mathrm{CEI} 60247$ & & & $<0.008$ \\
\hline \multicolumn{4}{|l|}{ Breakdown voltage $(\mathrm{kV})$} \\
\hline D877 & 53 & & \\
\hline CEI 60156 & & $<75$ & $<75$ \\
\hline Gassing tendency $(\mu \mathrm{L} / \mathrm{min}), \mathrm{D} 2300 \mathrm{~B}$ & +17 & - & - \\
\hline Water content (ppm), D 1533 & 20 & - & 50 \\
\hline $\begin{array}{l}\text { Interfacial tension (dynes/cm @ } \\
\left.25^{\circ} \mathrm{C}\right), \mathrm{D} 971\end{array}$ & 49 & - & - \\
\hline Total Acid Number & $<0.01$ & & $<0.03$ \\
\hline Viscosity (cSt@40ㄷ ), D 445 & 7.62 & 37 & 28 \\
\hline Color, D 1500 & $<0.5$ & $\begin{array}{c}\text { Pale } \\
\text { yellow }\end{array}$ & 125 \\
\hline Flash point $\left({ }^{\circ} \mathrm{C}\right), \mathrm{D} 92$ & 150 & 327 & 260 \\
\hline Pour point $\left({ }^{\circ} \mathrm{C}\right)$, D 97 & -62 & -31 & -60 \\
\hline
\end{tabular}

Determining the water content, DDF at line frequency and $100^{\circ} \mathrm{C}$, DDP, IFT and Turbidity of the fluid samples before the stability tests (Table 2), and comparing them with those obtained after (Table 3), assesses the outcome of random secondary chemical reactions between large fluid born free radicals.

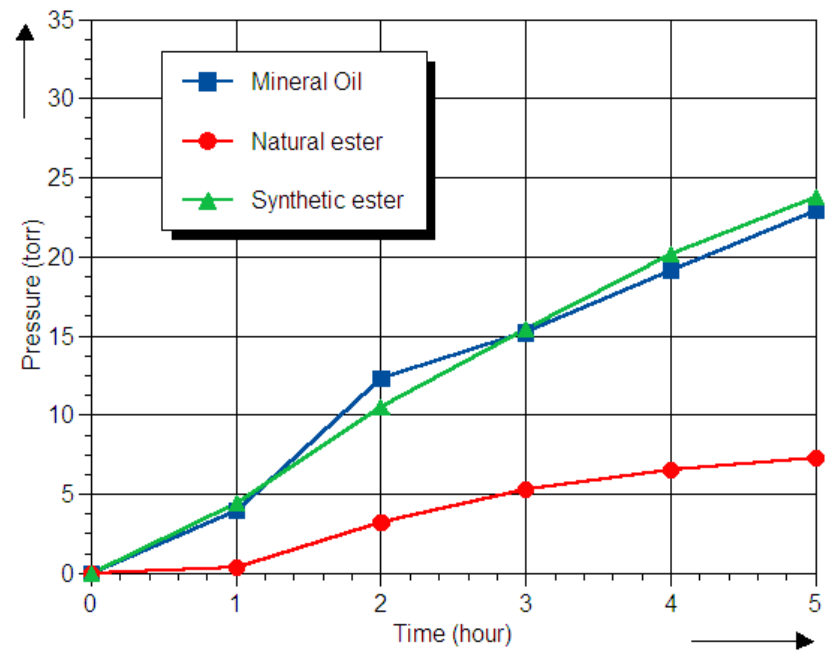

Figure 1. Insulating fluid samples gassing diagrams.

Obviously, the gassing tendency of natural esters is much lower than that of synthetic esters and mineral oils. This is well-known fact as emphasized in [12]. According to these authors, vegetable fluids are generally better than mineral 
oils. This can be traced to fact that the former are chemically better defined and more uniform, while mineral oils always contain various admixtures, and if they are excessively refined they may even lose traces of un-saturates that are actually desirable. This low gassing tendency of natural esters is most likely due to the amount of unsaturated, non-aromatic molecules as compared to mineral oils [11].

TABLE II. INSULATING FLUID SAMPLES ASSESSMENT BEFORE D6180 STABILITY TEST.

\begin{tabular}{lccc}
\hline & MO & NE & SE \\
\hline Water content (ppm) & 30.5 & 186 & 107.1 \\
DDF @60Hz, 100 C (\%) & 0.016 & 1.93 & 3.125 \\
DDP - D 6802 (area) & 11.58 & 22.03 & 5.1 \\
Interfacial Tension (IFT) & 43.4 & 23 & 23.5 \\
Turbidity D 6181 (NTU) & 0.29 & 0.35 & 0.47 \\
\hline
\end{tabular}

TABLE III. INSULATING FLUID SAMPLES ASSESSMENT AFTER D6180 STABILITY TEST.

\begin{tabular}{lccc}
\hline & MO & NE & SE \\
\hline Water content (ppm) & 11.1 & 183.5 & 283.7 \\
DDF @60Hz, 100 ${ }^{\circ} \mathrm{C}(\%)$ & 0.719 & 6,134 & 11.51 \\
DDP - D 6802 (area) & 36.78 & 28.66 & 4.34 \\
Interfacial Tension (IFT) & 34.5 & 20 & 21 \\
Turbidity D 6181 (NTU) & 2.19 & 1.91 & 0.95 \\
\hline
\end{tabular}

From the results reported in Tables 2 and 3 , it can be observed that the value of DDP after stability test increases because the large amounts of free radicals generated by the gassing of oil. At the same time the turbidity goes also up due to the secondary chemical reactions between the broken hydrocarbon chains. This observation is not obvious for synthetic esters which are more polar and have a larger solubility against sludge [13].

\section{Stability to AgEING}

Oxidation and aging are two main factors that can seriously affect the dependability of some fluids and affect the lifetime of transformers. Because the general life is much longer than the research duration, the investigation was based on studying the aging effect with increased speed. The ageing procedure is done by placing insulation specimens in a convection oven at $100^{\circ} \mathrm{C}$ and aging them for an extended specific period, with air (oxygen) inlet [14]. Typical transformer proportions of copper, aluminium, zinc and iron (each $3 \mathrm{~g} / \mathrm{l}$ ) were added to oil-paper insulation during the aging process in order to simulate the possible oxidation processes. The samples were aged for extended periods varying between 250 to 3100 hours, which simulate long time service condition due to the used severe aging conditions.

It should be noticed that "MO - $2000 \mathrm{~h}$ for example, means the dissipation factor of mineral oil sample with an aging duration of $2000 \mathrm{~h}$. An example of the frequency scans of the Dissipation Factor (DF) of the three fluid samples is given in Figure 2 while data at line frequency are provided in Figure 3. The measurements were performed with the Insulation Diagnostic Analyser IDA200 using the liquid test cell type 2903 for liquid insulants by Tettex. Figure 3 reflects the differences between new, slightly oxidized and heavily oxidized fluid samples; the DF almost increases during the accelerated aging tests.
The relative content of DDP in an aged fluid samples was numerically characterized from the absorbance curves according to ASTM D6802). The computed results are summarized in Figure 4. Out of this Figure, it can be observed that the rate of DDP increase in mineral oil is much higher than that of synthetic ester (5-7 times higher than in synthetic ester fluid after 3,100 hours aging). Natural ester shows an intermediate behaviour.

Results reported in Figure 5 were performed according to ASTM D6181. Again, the same observation as for the DDP applies.

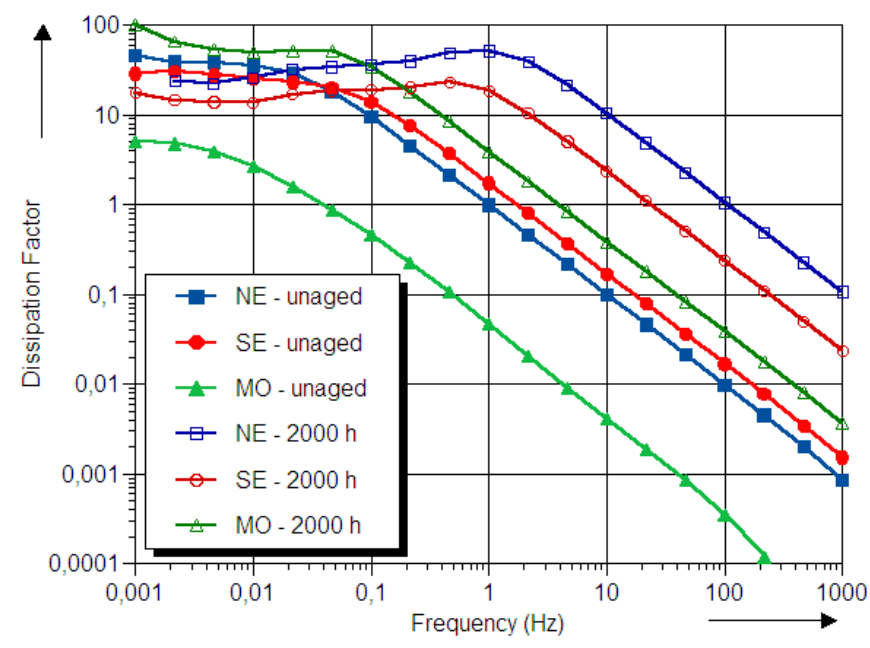

Figure 2. Frequency scans of the dissipation Factor for laboratory-aged fluid samples.

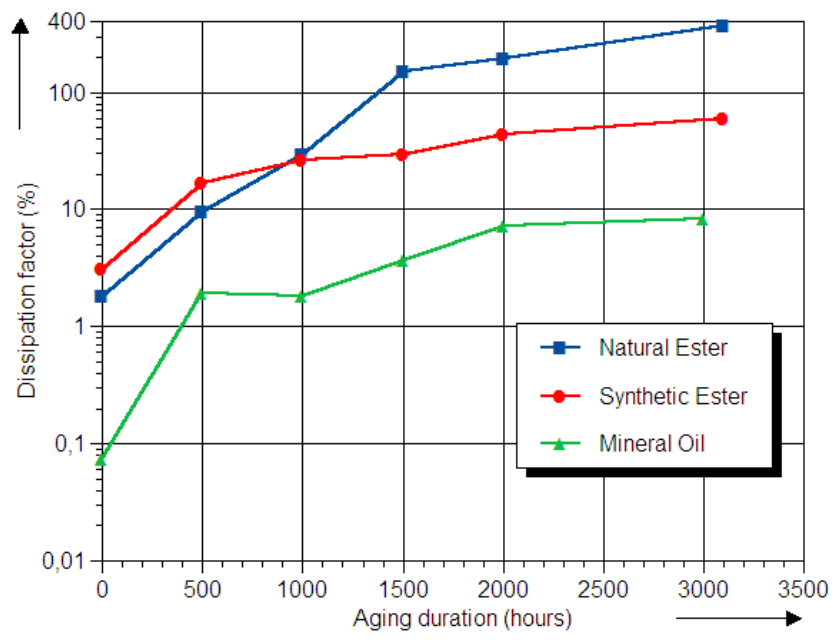

Figure 3. Dissipation Factor for laboratory-aged fluid samples at line frequency as a function of ageing duration.

The amount of microscopic solid suspension in both new and in aged fluid samples was also determined and summarized in Figure 5. The solid suspension content inside mineral oil increases 3-5 hundreds times than in ester fluids after 3,100 hours aging.

Even though the DF values obtained for mineral oil are lower than those of esters (Figures 2 and 3), the amount of decay products is retentively high.

Actually, oxidation process inside oil is controlled or slowed down by preventive maintenance procedures by incorporating oxidation inhibitors or antioxidants with the 
aim of interrupting and terminating the free radical process of oxidation. Inhibitors used in transformer oils offer stability for a limited time, the so-called the 'induction period' after which the oil oxidizes at the normal uninhibited rate. The commercial MO used in these investigations contains $0.08 \%$ of oxidation inhibitor content. From the obtained results, this phenomenon seems to happen after 1000 hours aging duration. Figures 4 and 5 might be related to this striking phenomenon.

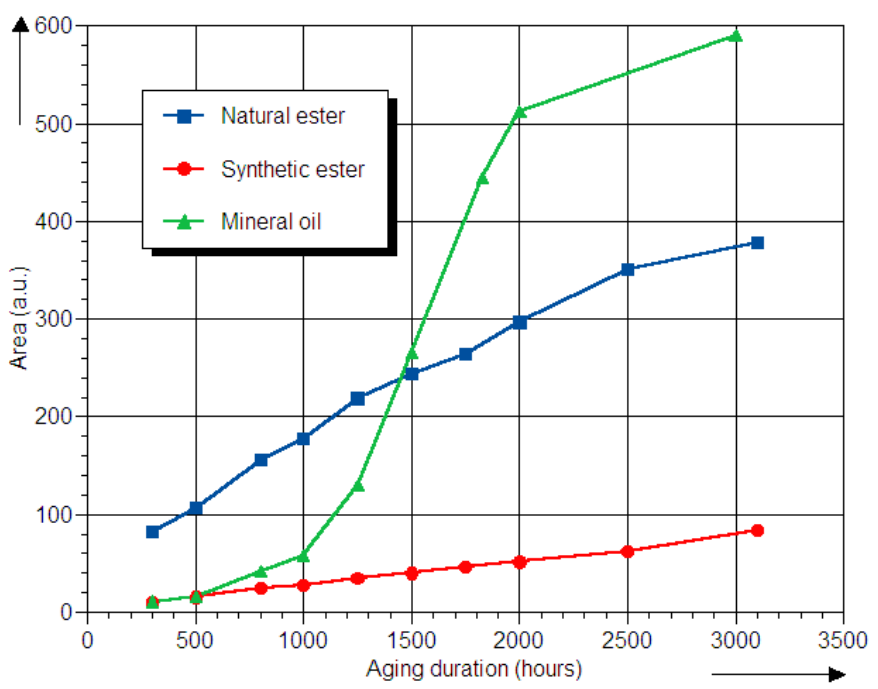

Figure 4. Relative content of the Dissolved Decay Products as function of ageing duration for different fluids.

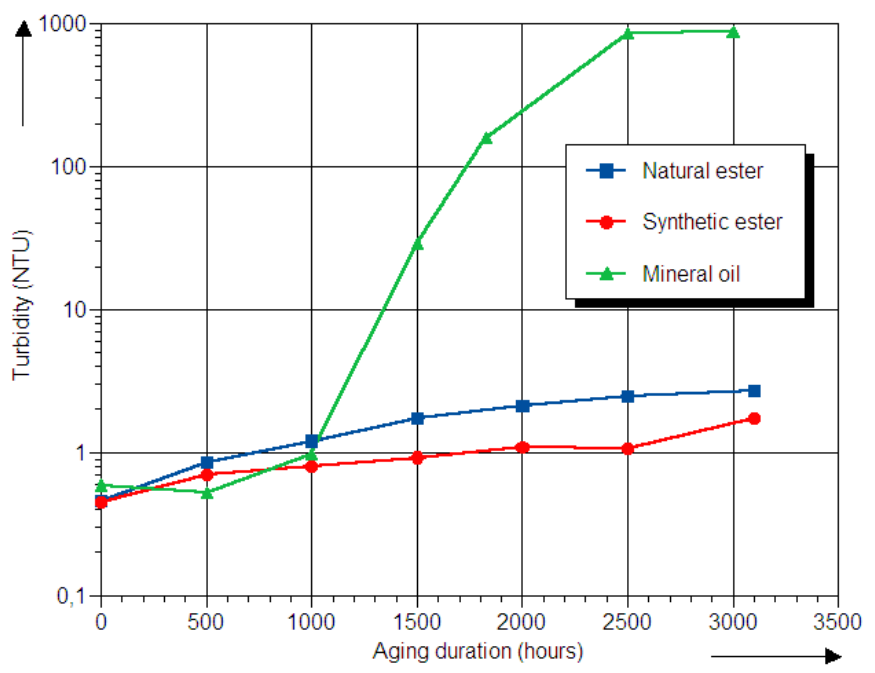

Figure 5. Turbidity as function of ageing duration for different fluids.

The oxidation stability (or capability to resist oxidation) of synthetic ester is to be emphasized, demonstrating its excellent oxidation stability.

\section{CONCLUSIONS}

A study to evaluate the stability to oxidation and gassing under electrical stress of commercially available insulating fluids was undertaken.

Whilst the D6180 stability test accurately measures the gases evolved, it also reveals the side effects of gassing due to the secondary chemical reactions between broken molecules. The results indicate that the gassing tendency of natural esters is much lower than that of the other fluids. This is not to say that natural esters are superior to mineral oils/synthetic fluid. Each Fluid type has its advantages and disadvantages and must be fitted to the application. No significant differences between the synthetic ester and mineral oil were observed.

From the investigations with the available commercial fluids, we find that synthetic ester ages considerably slower than the natural ester dielectric fluid and mineral oil under the same aging condition; the natural ester showing an intermediate behaviour. Even though the DF values obtained for mineral oil are lower than those of esters, the amount of decay products is retentively high. Moreover, ester liquid has an excellent ability to dry the solid insulation when they are partnered. Ester fluids can hold considerably more water than can mineral oil [14]. Because of the difference in saturation levels, ester fluids can absorb more water than mineral oil, and so has a greater paper drying ability. At elevated temperatures, ester fluids can undergo hydrolysis, consuming available water from the paper, thereby reducing the water damage potential, and improving paper ageing characteristics. Also, the esterification of the reactive $\mathrm{OH}$ sites on cellulose with bulky ester groups stabilizes the molecule and extends thermal life of the solid insulation.

\section{REFERENCES}

[1] N. Berger, "Liquides Isolants en Électrotechnique," Techniques de l'ingénieur, D 2470.

[2] I. Fofana and J. Sabau, "Application of Petroleum-based oil in Power Transformer," 23 pages, In Natural Gas Research Progress, Editors: Nathan David and Theo Michel, (C) 2008 Nova Science Publishers, Inc., ISBN: 978-1-60456-700-7.

[3] D. P. Stockton, J. R. Bland, Jr., Todd McClanahan, M. Wilson, D. L. Harris and P. McShane, "Seed-Oil-based coolants for transformers," IEEE Industry Applications Magazine, pp. 68-74, Jan/Feb 2009.

[4] ASTM Designation 6180, Standard Test Method for Stability of Insulating Oils of Petroleum Origin under Electrical Discharge, Vol. 10.03, 2008.

[5] ASTM Designation 924 - 08, Standard Test Method for Dissipation Factor (or Power Factor) and Relative Permittivity (Dielectric Constant) of Electrical Insulating Liquids, Vol. 10.03, 2008.

[6] ASTM Designation 6802, Test Method for Determination of the Relative Content of Dissolved Decay Products in Mineral Insulating Oils by Spectrophotometry, Vol. 10.03 .

[7] ASTM Designation 6181, Standard Test Method for Measurement of Turbidity in Mineral Insulating Oil of Petroleum Origin, Vol. 10.03

[8] ASTM Designation 971, Standard Test Method for Interfacial Tension of oil against water by the ring method, Vol.10.03.

[9] ASTM Designation 1533, Standard Test Method for Water in insulating liquids by Coulometric Karl fisher Titration, Vol. 10.03.

[10] Insulation Diagnostics Spectrometer IDA, Programma Electric AB, Eldarv. 4, SE-187 75 Täby, Sweden.

[11] L. Lewand, "Laboratory Testing of Natural Ester Dielectric Liquids," Neta World, Winter 2004 pp. 1-4.

[12] B. P. Kang, "Stability of Electrical-Insulating Oils," IEEE Transaction on Dielectrics and Electrical Insulation, Vol. 5, Issue 2, June 1970.

[13] I. Fofana, A. Bouaicha, M. Farzaneh, J. Sabau and D. Bussières, "Decay Products in the Liquid Insulation of Power Transformers," IET Electric Power Applications, Vol. 4, Iss. 3, pp. 177-184, 2010.

[14] I. Fofana, H. Borsi and E. Gockenbach, "Oil Filled Transformer Retrofilled with ester Liquid - Facts and Arguments," $15^{\text {th }}$ ISH 2007 , Ljubljana, Slovenia, August 27-31, 2007. 